\title{
CHLORAMPHENICOL (CHLOROMYCETIN) IN THE TREATMENT OF TSUTSUGAMUSHI DISEASE (SCRUB TYPHUS)
}

\author{
By JOSEPH E. SMADEL, THEODORE E. WOODWARD, HERBERT L. LEY, JR., \\ AND RAYMOND LEWTHWAITE
}

\author{
(From the Army Medical Department Research and Graduate School, and the Commission on \\ Immunization of the Army Epidemiological Board, Washington, D. C.; the \\ University of Maryland School of Medicine, Baltimore; and the \\ Institute for Medical Research, Kuala Lumpur)
}

(Received for publication May 3, 1949)

The present paper augments information previously published on the first 25 patients with scrub typhus to receive chloromycetin (1) and reviews our experience in the use of this drug in the treatment of a total of 69 persons who contracted tsutsugamushi disease in the vicinity of Kuala Lumpur, Federation of Malaya. The results obtained in this group are compared with those observed in 19 patients with the disease who received only supportive therapy and in three who were given $\mathrm{p}$-aminobenzoic acid.

\section{MATERIALS AND METHODS}

Chloromycetin. Chloromycetin ${ }^{1}$ prepared by the fermentation process was supplied for the current work by Parke, Davis and Company. A small amount of the antibiotic, subsequently administered in capsules, was received as pure crystalline material but almost all of the drug was in the form of tablets containing $0.25 \mathrm{gm}$. amounts of active crystalline material. All treatment was by the oral route.

The levels of chloromycetin in the serum and other body fluids were determined by a modification (2) of the technique described by members of the Research Laboratories of Parke, Davis and Company (3). This is a turbidimetric bioassay method in which the amount of drug in a known standard required to produce 50 per cent inhibition of growth of Shigella paradysenteriae (Sonne) ${ }^{2}$ is compared with the inhibiting capacity of varying dilutions of the unknown material.

Isolation of rickettsiae. The presence of rickettsemia in patients was demonstrated in the following manner. Freshly drawn blood was defibrinated, by shaking with glass beads, and centrifuged; the plasma was discarded and the sedimented red cells were resuspended in an equal volume of physiological saline solution. One-half cc. of such a suspension was injected intraperitoneally

1 Chloramphenicol is now the generic name for the antibiotic originally designated chloromycetin. Chloromycetin has been reserved as a trade name by Parke, Davis and Company.

2 This organism is now classified by Bergey (1948) as Shigella sonnei. into each of four normal young adult albino mice of one of several inbred lines. Mice inoculated with blood containing rickettsiae generally showed signs of illness between the ninth and 12th days, and died between the 11 th and the 14th. With few exceptions, the rickettsial strains recovered in the vicinity of Kuala Lumpur were highly virulent for mice, and usually all of the animals which received the infected blood died unless sacrificed for study. One mouse from the original group was sacrificed when it first showed signs of illness or on the 12th day. When the results were positive, these animals displayed the typical gross pathological changes of experimental Rickettsia tsutsugamushi infection in mice, i.e., enlargement of lymph nodes and injection of vessels observed when the ventral skin was reflected, sero-gelatinous peritoneal exudate, enlargement of the spleen, and accumulations of pleural fluid. Impression smears from the surface of the spleen and scrapings from the peritoneal surface of the abdominal wall, when stained by Giemsa's method, contained intracellular rickettsia-like organisms. The presence of such macroscopic lesions and the finding of rickettsiae microscopically were considered presumptive evidence of $R$. tsutsugamushi infection. Almost without exception rickettsiae were demonstrated microscopically in at least two of the four mice originally injected with the patient's blood. Furthermore, in the majority of instances a splenic suspension of material, or peritoneal exudate, from a mouse of the original group was passed by intraperitoneal injection to a second group of four normal animals in which the disease picture was reproduced. On a number of occasions the agent was maintained for several months by serial passages in mice. The strain obtained from treated Patient 9 was used as challenge material to demonstrate the immunity of occasional mice convalescent from infections with other strains and to determine whether mice had had inapparent infection following inoculation with a patient's blood. Seven of the strains were brought to the Army Medical Department Research and Graduate School where they were shown by reciprocal crossimmunity tests to be related to the well known Karp strain of $R$. tsutsugamushi. It was our experience that the attempted isolation of rickettsiae from blood of patients generally gave clean-cut results in the original mice. Thus, the employment of the blind passage technique and the testing of surviving mice for immunity by challenge with known lethal amounts of rickettsiae 
rarely yielded indications of rickettsemia in the patient unless the original mice had shown obvious disease. It may be noted that strains of $R$. tsutsugamushi found in different geographical areas vary considerably in their pathogenicity for mice (4). Therefore, it was fortuitous and fortunate that the Malayan strains were relatively easy to recover and identify.

Serological tests. Weil-Felix tests were performed using standardized suspensions of $\mathrm{OX}-\mathrm{K}$ and $\mathrm{OX}-19$ strains of Bacillus proteus according to the technique of the Army Medical Department Research and Graduate School (5) or that of the Institute for Medical Research. Specific complement-fixation tests employing the washed rickettsial antigens of $R$. prowazeki and $R$. mooseri (6) were done in selected instances. Similarly, agglutination tests for Leptospira icterohemorrhagiae were performed on specimens from certain patients by the Veterinary Division of the School.

Routine clinical laboratory procedures. Erythrocyte and leukocyte counts and differential white blood cell counts were made in the usual manner. Hemoglobin values were determined spectrophotometrically by the cyanomethemoglobin method (7) and the usual procedures were employed for urinalysis. Blood levels of para-aminobenzoic acid were determined by a colorimetric procedure (8).

\section{RESULTS}

\section{Patients with scrub typhus acquired during normal occupational duties}

Selection of patients. Thirty patients who acquired scrub typhus during normal occupational duties were treated with chloromycetin. Twentyeight of these contracted their disease in the vicinity of Kuala Lumpur. Twelve of the group became infected while working at the Seaport Estate between Kuala Lumpur and Batu Tiga (see Figure 1). The air field on the outskirts of Kuala Lumpur provided four of the cases who were treated. The remaining 12 occurred singly or in small groups within a 20 mile radius of the Institute for Medical Research. Patient 9 contracted his infection in Singapore and Patient 49 acquired hers following an accident at the Army Medical Department Research and Graduate School while handling the strain from treated $\mathrm{Pa}-$ tient 25.

The course of the disease in patients who were given only supportive treatment was recorded in 19 persons who were observed during the period of the study. All of these acquired their infection in the general area which supplied the majority of the patients who received chloromycetin and five of them became infected on Seaport Estate. These untreated patients were observed during periods when a supply of the specific antibiotic was not available, or the drug was withheld because they were first seen late in the disease and were not then desperately ill.

No effort was made to restrict the administration of chloromycetin to alternate patients who came under study. A precise balance could not have been obtained in this relatively limited investigation by selecting alternate patients for treatment unless certain important factors were evenly distributed in the treated and control groups; a few of these factors were age, sex, race, history of previous exposure in infected areas, and the virulence of the infecting strain of $R$. tsutsugamushi. Nevertheless, many of these variables were eliminated in the group of 17 patients from Seaport Estate in which five served as untreated controls. Early in the work it became quite clear that the course of the disease in the treated patients was markedly different from that observed in untreated persons in the current group or in patients with scrub typhus who had been studied during the preceding 20 years by members of the Institute for Medical Research (9-11). This marked difference in response of treated and untreated patients greatly simplified the interpretation of results.

Observations on patients with scrub typhus given supportive treatment. Detailed data on the 19 cases of scrub typhus who did not receive specific therapy are given in Table I. The more pertinent information is summarized in Table II. As the tabular data indicate, the average duration of fever in this group of persons was 17.1 days with extremes of 12 and 31 . The course of the disease was complicated in two of the 19 patients by pneumonia and one of them died as a result. A third patient had suppurative parotitis which required surgical intervention.

All of these untreated patients were diagnosed on the basis of the history, clinical findings, and a positive Weil-Felix reaction. The diagnosis was further established in untreated Patient 16 by recovery of $R$. tsutsugamushi from the patient's blood.

Observations on patients with scrub typhus treated with chloromycetin. Information on each of the 30 treated patients and a summary of certain of the data are given in Tables II and III, respectively. The response following administra- 
TABLE I

UNTREATED CASES

KUALA LUMPUR, 1948

\begin{tabular}{|c|c|c|c|c|c|c|c|c|c|c|c|}
\hline \multicolumn{4}{|c|}{ PATIENT } & \multirow{2}{*}{$\begin{array}{l}\text { DATE } \\
\text { OF } \\
\text { ONSET }\end{array}$} & \multirow{2}{*}{$\begin{array}{l}\text { TYPE } \\
\text { OF } \\
\text { HOSP. }\end{array}$} & \multirow{2}{*}{$\begin{array}{c}\text { LAST FEBRILE } \\
\text { DAY OF } \\
\text { ILLNESS }\end{array}$} & \multirow{2}{*}{$\begin{array}{l}\text { COMP- } \\
\text { LICATIONS }\end{array}$} & \multicolumn{2}{|c|}{ OX-K TITER } & \multirow{2}{*}{$\begin{array}{l}\text { ISOLATION } \\
\text { OF } \\
\text { RICK. }\end{array}$} & \multirow{2}{*}{$\begin{array}{l}\text { DAY AFTER } \\
\text { ONSET DISCHD. } \\
\text { FROM HOSP. }\end{array}$} \\
\hline no. & AGE & SEX & RACE & & & & & ACUTE & CONV. & & \\
\hline 1 & 24 & $m$ & $m$ & 3 FEB & MIL & 21 & NONE & 80 & 320 & No & si \\
\hline 2 & 27 & $\mathbf{M}$ & E & $14 "$ & GEN & 17 & DEATH (17D) & 85 & 500 & $n$ & \\
\hline 3 & 50 & $M$ & I & $16 "$ & GEN & 18 & PAROTITIS & & 340 & " & 44 \\
\hline 4 & 17 & $\boldsymbol{m}$ & I & $20 "$ & GEN & 16 & NONE & 80 & 178 & $\bullet$ & 28 \\
\hline 5 & 18 & $\boldsymbol{M}$ & E & 22 " & MIL & 14 & $n$ & 160 & 640 & " & 30 \\
\hline 6 & 38 & $\mathbf{m}$ & 1 & $23 n$ & GEN & 12 & $n$ & 0 & 800 & $*$ & 28 \\
\hline 7 & 80 & $\mathbf{M}$ & 1 & $25 n$ & GEN & 23 & $\bullet$ & & 640 & * & 34 \\
\hline 8 & 27 & $m$ & c & $26 *$ & GEN & 18 & " & 280 & 880 & $\bullet$ & 28 \\
\hline - & 29 & $m$ & m & II MAR & GEN & 13 & n & & 8000 & $n$ & 21 \\
\hline 10 & 50 & $m$ & 1 & $13 N$ & EST * & 19 & " & & 800 & $n$ & 36 \\
\hline 11 & 48 & M & 1 & $19 *$ & EST * & 14 & $n$ & 128 & 1280 & " & 30 \\
\hline 12 & 30 & $M$ & I & 280 & GEN & 24 & $"$ & & 2300 & ${ }^{*}$ & 31 \\
\hline 13 & 30 & $\mathbf{F}$ & 1 & 29 & EST * & 14 & n & & 2560 & $\omega$ & 22 \\
\hline 14 & 48 & $m$ & c & SAPR & GEN & 18 & $\omega$ & $\infty$ & 500 & $"$ & 28 \\
\hline 15 & 30 & $m$ & 1 & 9 & GEN & 31 & PHEUMONIIA & 1000 & 8120 & 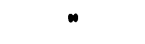 & 48 \\
\hline 36 & 26 & $m$. & $m$ & $10 n$ & GEN & 12 & MONE & & 320 & Pos & 17 \\
\hline 17 & 53 & $\mathbf{F}$ & 1 & $18 "$ & EST * & 14 & $"$ & & 640 & ND & 22 \\
\hline 18 & 38 & $\mathbf{F}$ & 1 & o mar & EST * & 13 & $n$ & & 640 & $"$ & 28 \\
\hline 19 & 24 & 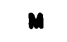 & 1 & 2 JUNE & MIL & 13 & $\infty$ & & 320 & $n$ & 28 \\
\hline AV & & & & . & & 17.1 & & & & & 29.8 \\
\hline
\end{tabular}

RACE: C = CHINESE, E = EMGLISH, I= IMDIAN, ME MALAY HOSP: EST = ESTATE, GEN = GEMERAL, MIL = MILITARY ISOLATION OF RICK: ND= MOT DONE

- these patients contracted their disease and were treated on seaport estate

TABLE II

SCRUB TYPHUS PATIENTS

KUALA LUMPUR, 1948

\begin{tabular}{|c|c|c|}
\hline & TREATED & UNTREATED \\
\hline NO. PATIENTS & $\begin{array}{rr}30 & 23 \text { MALES } \\
& 7 \text { FEMALES }\end{array}$ & 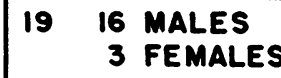 \\
\hline $\begin{array}{l}\text { DAY AFTER ONSET } \\
\text { R BEGUN }\end{array}$ & 3 TO II AV 6.2 & \\
\hline $\begin{array}{l}\text { LAST FEBRILE DAY } \\
\text { OF ILLNESS }\end{array}$ & 4 TO 12 AV 7.4 & 12 TO 31 aV 17.1 \\
\hline $\begin{array}{l}\text { DURATION OF FEVER } \\
\text { AFTER R BEGUN(HR) }\end{array}$ & 6 TO 96 aV 31.8 & • \\
\hline $\begin{array}{l}\text { DAY AFTER ONSET } \\
\text { DISCH'D FROM HOSP }\end{array}$ & 14 TO 28 AV 17.8 & 17 TO 51 AV 29.9 \\
\hline COMPLICATIONS & 0 & $\begin{array}{l}\text { I PAROTITIS } \\
\text { I PNEUMONIA }\end{array}$ \\
\hline DEATHS & 0 & $17^{\text {th }}$ DAY \\
\hline MONTH OF ONSET & MARCH - SEPT & FEB - JUNE \\
\hline
\end{tabular}


CHLOROMYCETIN IN TREATMENT OF SCRUB TYPHUS

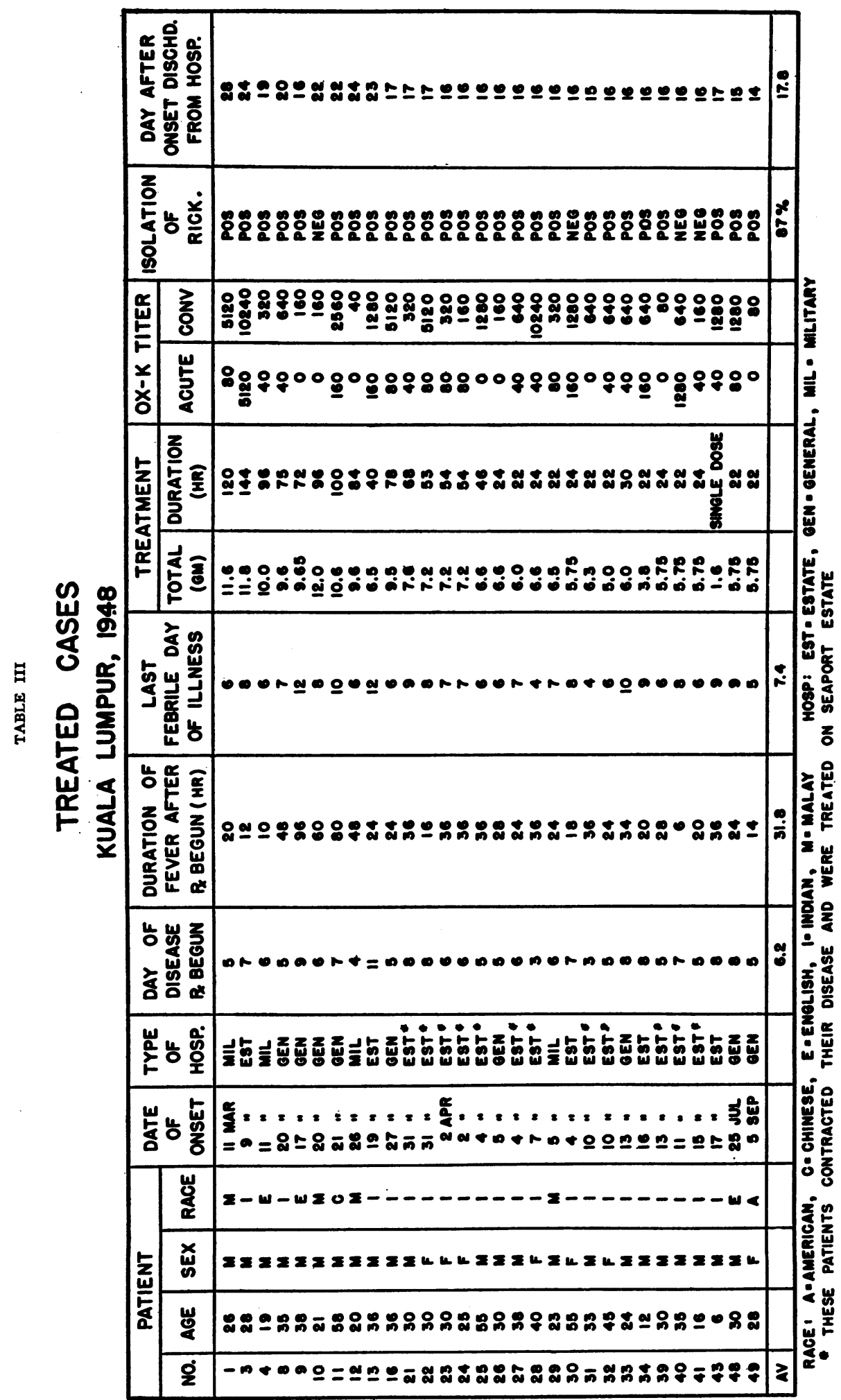




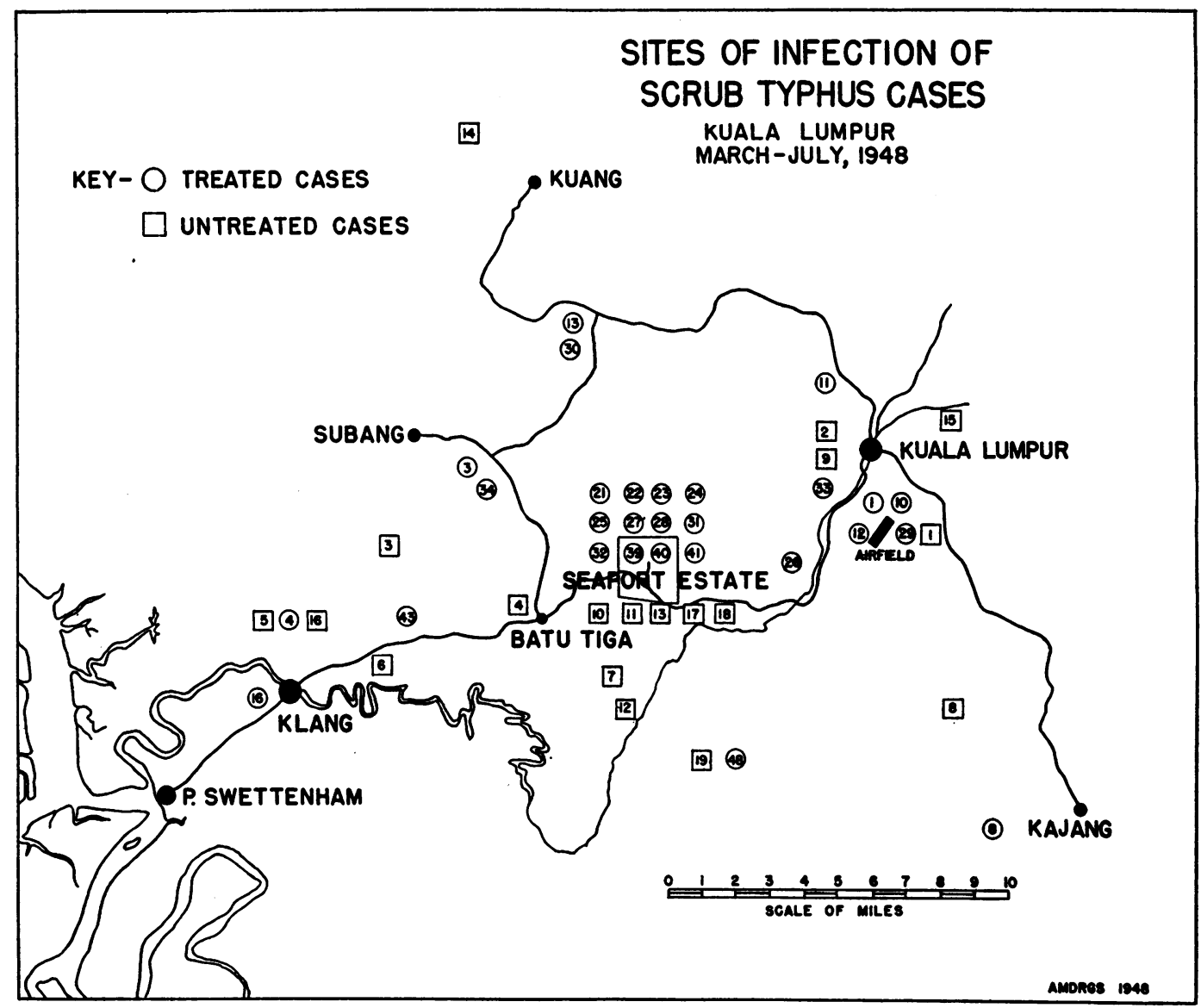

FIG. 1

tion of chloromycetin has been so consistent that it will be sufficient to present certain illustrative cases and to draw general conclusions.

All cases were given an initial oral dose of chloromycetin of about $60 \mathrm{mg} . / \mathrm{kg}$. of body weight. Since most of the patients were of small stature and weighed from $50-60 \mathrm{~kg}$., this initial dose was usually between 3.0 and 3.5 gms. Following this dose, the patients were maintained for a variable period of time on $0.25 \mathrm{gm}$. amounts of drug administered at intervals of three hours. For example, treated Patient 1, whose clinical record is graphically presented in Figure 2, followed this regime for 48 hours and was then maintained on drug in reduced amounts for the three succeeding days. This patient who was started on chloromycetin on the fifth day became afebrile within 20 hours and remained free of fever thereafter. As therapeutic experience increased the total amounts of drug and the duration of therapy were reduced (see Table III). Treated Patient 29, whose record is illustrated in Figure 3, was started on specific therapy on the sixth day and received a total of 6.5 gms. over a period of 22 hours. He became afebrile within 24 hours after the initial dose. A short course of drug such as used for Patient 29 provided results which appeared to be as satisfactory as those obtained when larger amounts were given over a period of four or five days.

The clinical diagnosis of scrub typhus was confirmed in each of the 30 patients by demonstration of rickettsemia or the development of a positive Weil-Felix reaction (see Table III). Rickettsiae were isolated from the bloods of 26 of the 30 patients. At least a four-fold increase in titer of agglutinins for the OX-K strain of $B$. proteus was shown to develop during convalescence in 28 of the patients. Convalescent sera from treated cases Nos. 12 and 24 had OX-K agglutinins in low titer 

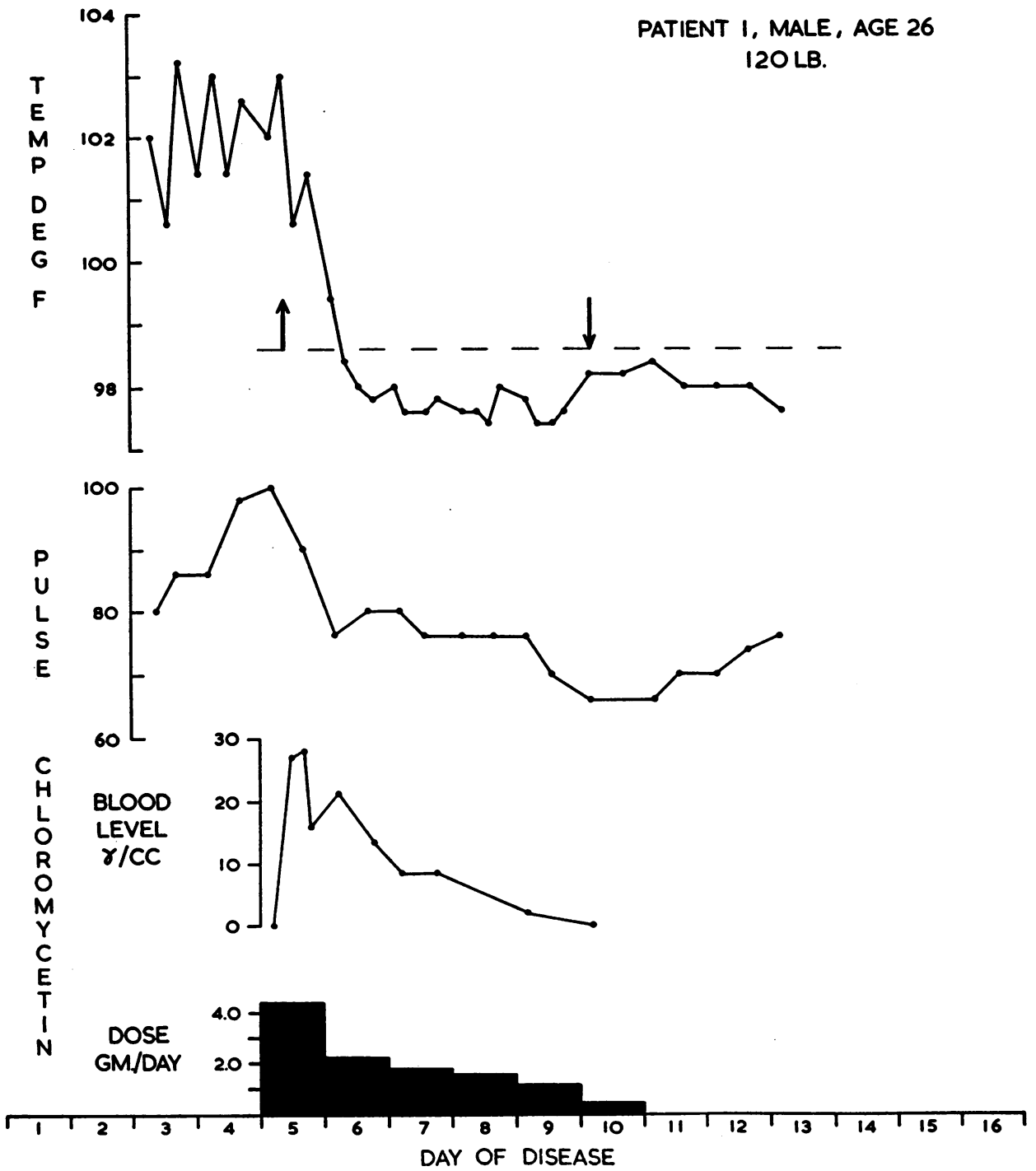

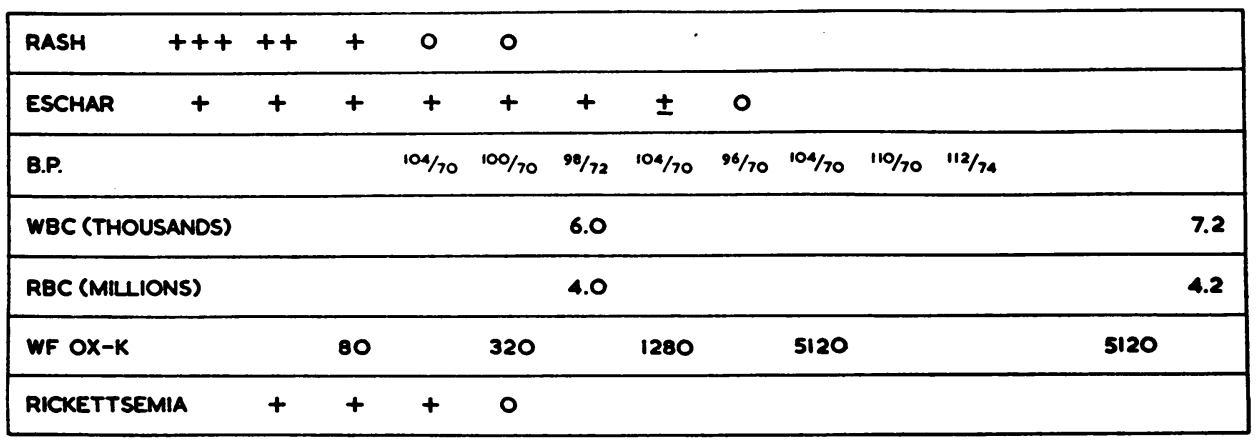

Fig. 2. Clinical Response of Patient 1 to Chloromycetin Therapy Begun on the Fifth Day of Disease

A total of $11.6 \mathrm{gms}$. of chloramphenicol was given over a period of 120 hours. 
but did not contain a significant increase over the acute phase sample. The diagnosis was established, however, in each of these patients by the isolation of $R$. tsutsugamushi.

A comparison of the results obtained in the treated and untreated groups of patients is given in Table II. In the treated cases recovery began within a matter of hours after specific therapy was instituted, and fever lasted from six to 96 hours after chloromycetin was begun; the average duration being 31.8 hours for the entire group of 30 patients. It may be mentioned that treated $\mathrm{Pa}$ - tient 9, who required 96 hours to become afebrile, was irrational, cyanotic and in extremis when treatment was started late on the ninth day. Although defervescence was slow this patient began to improve clinically within 12 hours after the antibiotic was administered, for at that time he sat up in bed and complained because breakfast was inadequate. It is worthy of note that chloromycetin therapy was equally effective whether given early or late in the disease. Thus, treated Patients 28 and 31, who were first seen on the third day, required 36 hours to become afebrile
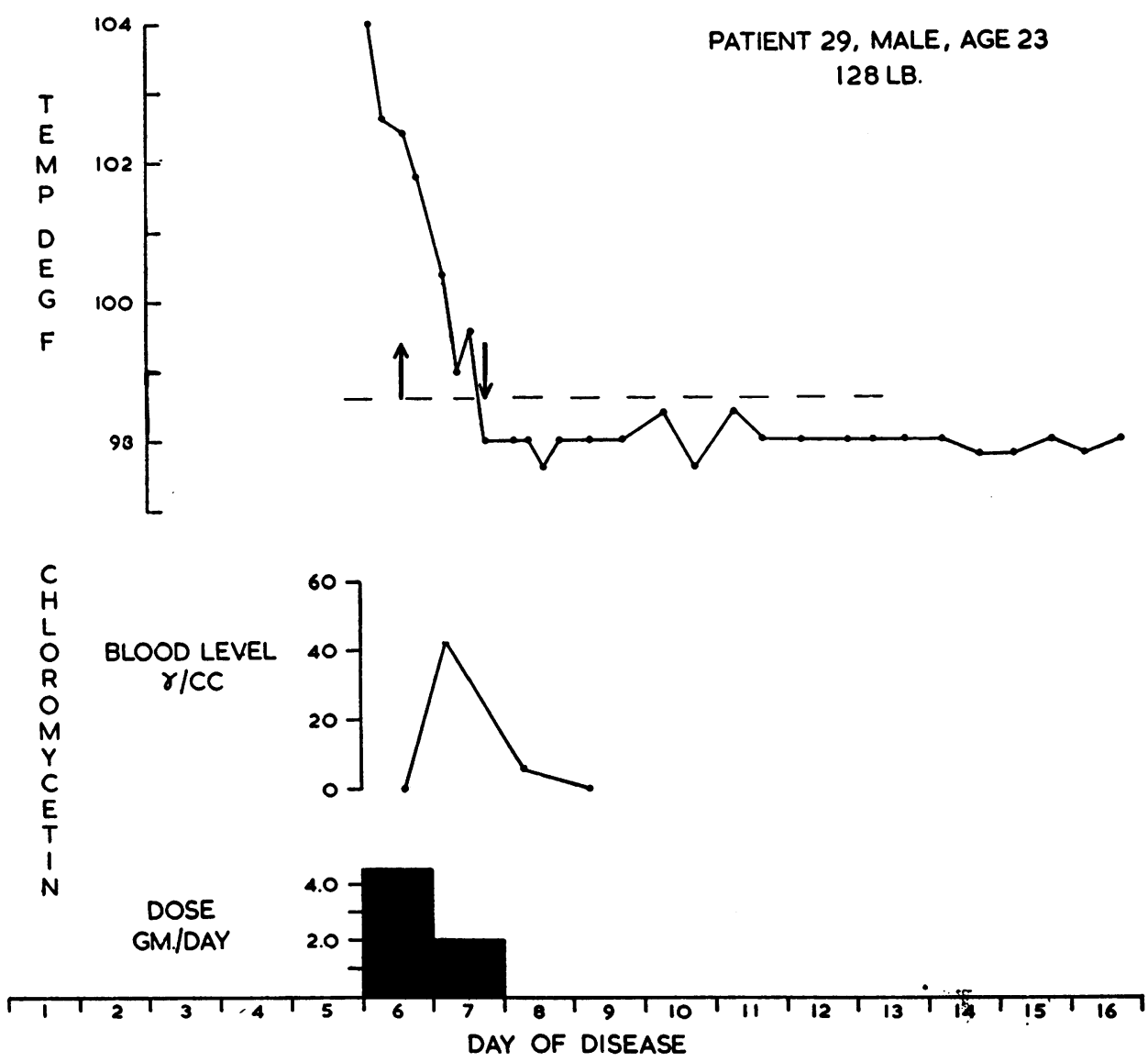

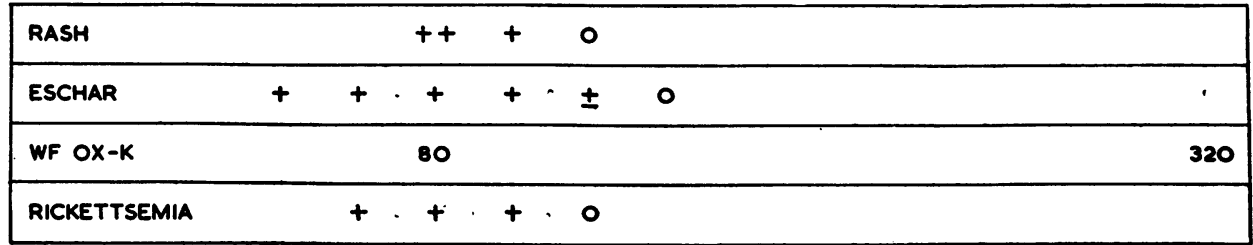

Fig. 3. Clinical Response of Patient 29 to Chloromycetin Therapy Begun on the Sixth Day of Disease

A total of 6.5 gms. of chloramphenicol was given over a period of 22 hours. 

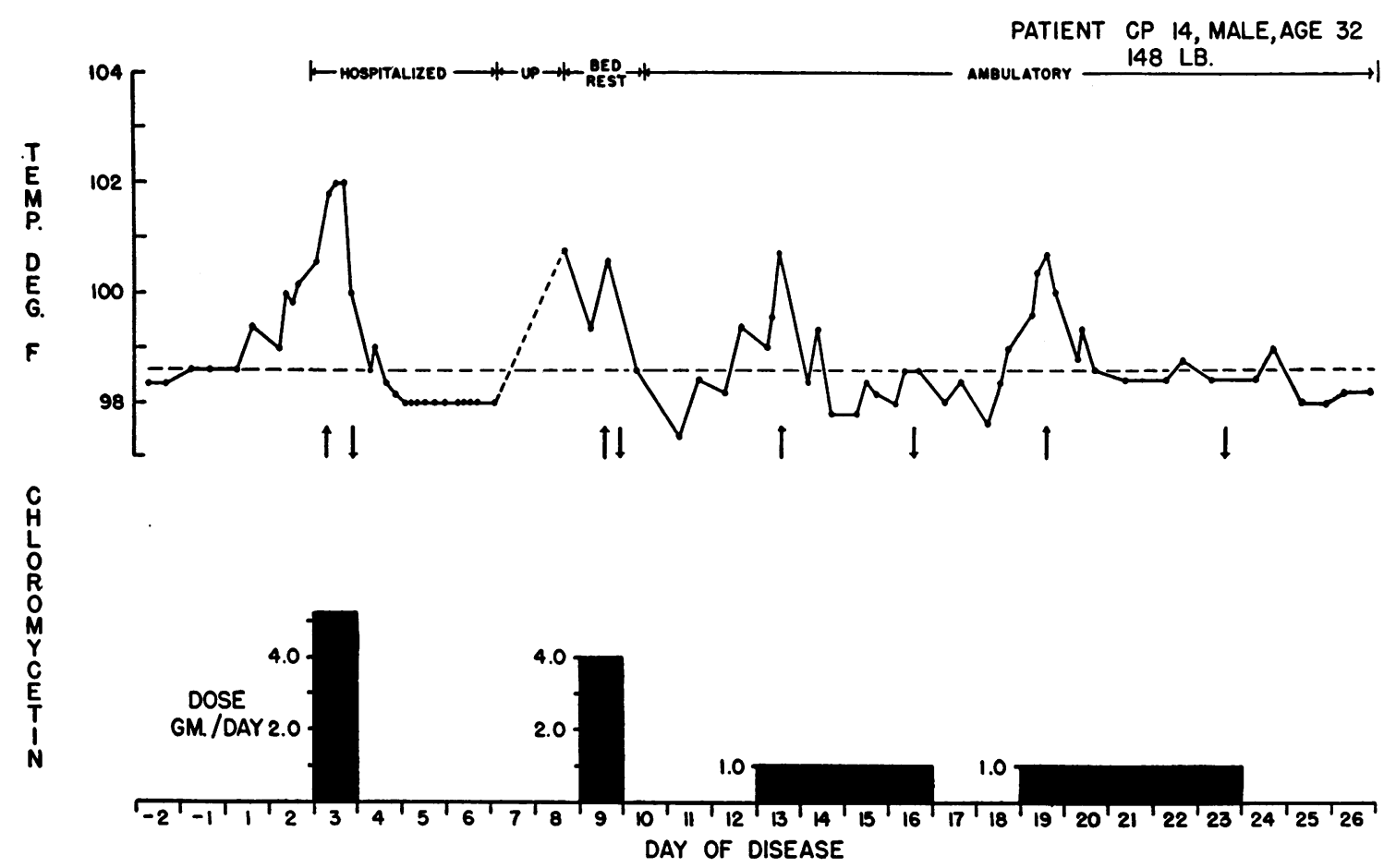

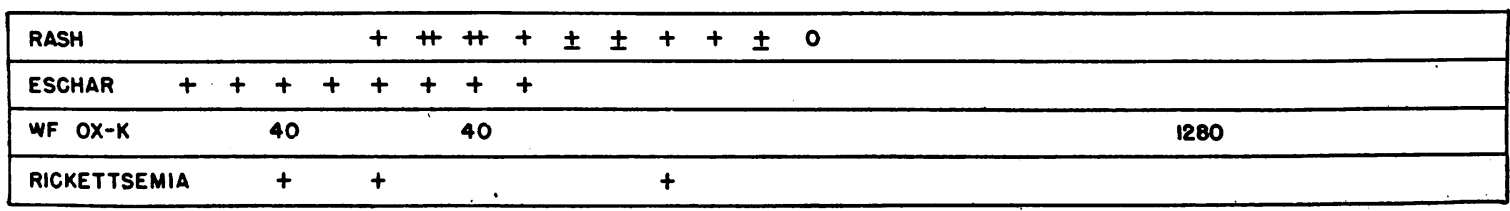

Fig. 4. Clinical Response of Patient CP 14 to Chloromycetin Therapy Begun on the Third Day of Disease

He relapsed on three occasions, each recurrence responded promptly to additional treatment with chloromycetin.

while treated Patient 13, who was given the antibiotic on the 11th day, became afebrile within 24 hours. The average day on which therapy was begun for the treated group was 6.2 and the last febrile day of the illness was 7.4. This may be compared with that of the last febrile day of illness in the untreated group; this varied between 12 and 31 and averaged 17.1 days.

The first treated patient, although afebrile on the sixth day after onset, was kept in the Military Hospital until the 28th day. As additional patients were added to the series the period of hospitalization steadily diminished from four weeks to about two weeks (see Table III). The average for the entire group was 17.8 days $^{3}$ which con-

3 Treated patients were generally up and about in the hospital and grounds within a few days after becoming afebrile but they were kept in the hospital, although ap- trasts with an average hospitalization of 29.9 days in the untreated group. There were no complications and no deaths among the treated patients whereas among the untreated persons one died and two others had serious complications.

\section{Patients with other diseases who received chloromycetin}

The cases of suspected scrub typhus destined for specific therapy were numbered serially as they came under observation. It is apparent from Table III that the 30 patients with scrub typhus were culled from a series of 49 persons who were originally thought to have tsutsugamushi disease. Treated Patients 44 and 45 who are listed in

parently fully recovered, in order to permit medical observation and to prevent their returning to occupational duties. 
Table IV suffered from scrub typhus but because of the circumstances surrounding the acquisition of their disease they are not included in the present group. Treated Patients 46 and 47, Gurkah soldiers who acquired scrub typhus during jungle fighting, are reported in detail elsewhere (12) and will not be included in this group. These were the first two persons to receive the synthetic form of chloromycetin. Among the remaining 15 cases who were treated with chloromycetin, two (Nos. 18 and 19) had typhoid fever (13) and three (Nos. 6, 7, and 35) had murine typhus (14), two (Nos. 36 and 42) were infected with Leptospira icterohemorrhagiae, and one (No. 37) had malarial hematinuria (blackwater fever). No definitive diagnosis was established for the remaining seven patients (Nos. 2, 5, 14, 15, 17, 20, and 38) but all recovered promptly; the contribution of chloromycetin to their recovery could not be assessed. The efficacy of chloromycetin in the treatment of patients with typhoid fever and murine typhus has been commented upon elsewhere $(13,14)$. Neither of the cases of leptospirosis showed marked benefit from chloromycetin during the 24 to 48 hours it was given, at the end of which time the original tentative diagnosis of scrub typhus was changed, penicillin therapy was instituted, and improvement began shortly. The patient with blackwater fever recovered without clinically apparent kidney damage after institution of antimalarial and alkali therapy.

\section{The treatment of volunteers who contracted scrub typhus in hyperendemic areas}

Thirty-seven of the 75 volunteers who were exposed in hyperendemic areas of scrub typhus in the vicinity of Kuala Lumpur during the course of chemoprophylactic tests (15) developed tsutsugamushi disease. In these tests members of the control group developed scrub typhus during the second and third week after initial exposure while those individuals who received the antibiotic prophylactically, during exposure and the succeeding two weeks, remained well until the second week after drug was discontinued. The ultimate attack rate was not significantly different in the prophylactic and control groups of volunteers, and, except for the prolonged incubation period and the absence of eschar formation, there was no appreciable difference in the disease in volunteers of the two groups.

Data on the 37 volunteers who contracted scrub typhus are given in Table IV where, in addition, information is included on Patients 44 and 45 . In general, the volunteers were treated earlier in the course of their disease than were the patients discussed in the previous sections. For example, in a number of instances chloromycetin therapy was instituted on the first febrile day of illness and the average for the 37 volunteers was 3.1 days, which is exactly half that of the treated patients who acquired their disease under strictly natural conditions. Although there was some variation in the amount of drug given and the number of days over which therapy was provided, most of the patients received an initial oral dose of 4.0 gms. followed by a series of seven $0.25 \mathrm{gm}$. doses given at three hour intervals. The average duration of fever after drug therapy was started was 32.1 hours for this entire group. The averages for each of the four sub-groups consisting of those who had received chloromycetin prophylaxis and the controls in each of two field trials varied between 28.3 and 36.8 hours.

An unusual manifestation was noted in volunteers developing scrub typhus which had not previously been observed in patients who were treated symptomatically or in those mentioned in Table III who received chloromycetin therapeutically. This was the occurrence of relapses in volunteers who had apparently been cured by the initial course of drug. This phenomenon is discussed at some length in a report of the chemoprophylactic trials (15). However, it is of sufficient importance to review at this time. Twenty of the 37 volunteers who contracted tsutsugamushi disease in the two trials developed one or more relapses. The first recrudescence appeared between five to 15 days after the initial onset of disease. Since in most instances the initial therapeutic course had not exceeded 24 hours, the average interval between the last dose of drug used in the initial attack and the onset of the relapse was 7.1 days. Eight of the 20 patients had a second relapse which began on the average 6.5 days after the onset of the first recrudescence and 4.5 days after the end of therapy for the first relapse. Three of the group suffered from a third relapse. As in the first two recrudes- 
cences the interval between this and the preceding febrile episode was about one week.

Patients suffering from their first relapse were treated in essentially the same manner, receiving 3.0 to $6.0 \mathrm{gms}$. of drug during a period of 24 hours or less. The average duration of the recrudescent fever after beginning therapy was 24.3 hours. Those individuals who had second relapses received 3.0 to $5.75 \mathrm{gms}$. of drug, but the method of administration differed in this group. Patient CP5 received 3.0 gms. given in a single dose. Patient CP1 received $1.0 \mathrm{gm}$. daily for five days and the others were treated for a period intermediate between the two. Irrespective of the regime these patients became afebrile within a day. The three patients with third relapses had mild fevers in the range of $100^{\circ} \mathrm{F}$. which subsided rapidly whether or not therapy was given.

The diagnosis of scrub typhus was proved by laboratory procedures in all but one of the 37 volunteers who became ill with scrub typhus. These procedures consisted of either isolation of rickettsiae from the blood or the demonstration of the development of a positive Weil-Felix reaction (see Table IV). The initial relapses were proved to be scrub typhus in the majority of cases by demonstration of rickettsemia, i.e., in 11 of the 14 patients on whom attempts at isolation were made. Similarly, one of two patients examined had rickettsemia during his second relapse.
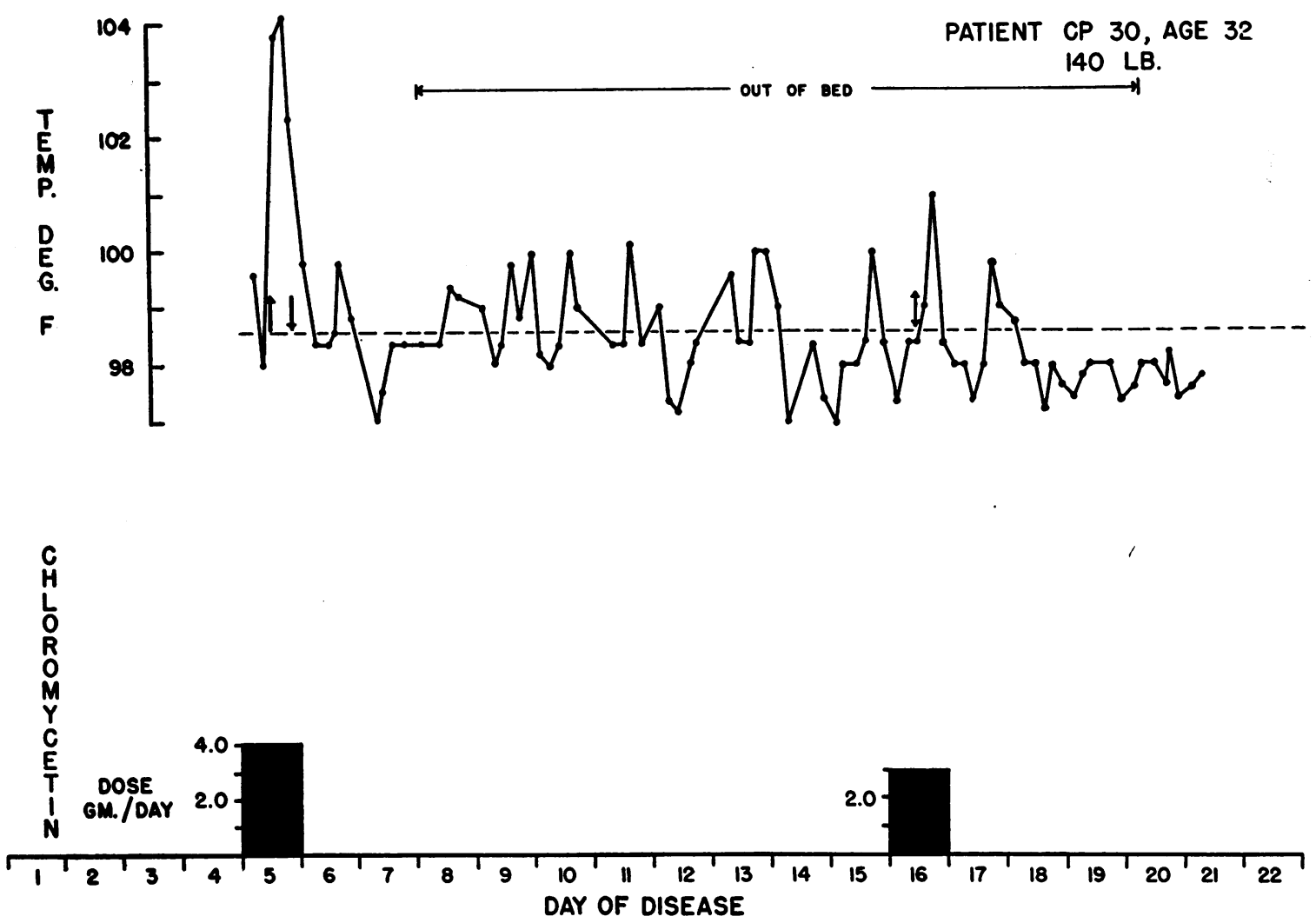

\begin{tabular}{|llcc|}
\hline WBC (THOUSANOS) & 5.6 & 9.5 & 7.7 \\
\hline RBC (MMLIONS) & 4.6 & 5.0 & 5.3 \\
\hline WF OX-K 160 & & 2560 & 2560 \\
\hline RICKETTSEMIA & & & \\
\hline
\end{tabular}

Fig. 5. Clinical Response of Patient CP 30 to Inadequate Chloromycetin Therapy Begun on the Fifth Day of Disease

The low grade intermittent fever subsided promptly after the second course of treatment. 


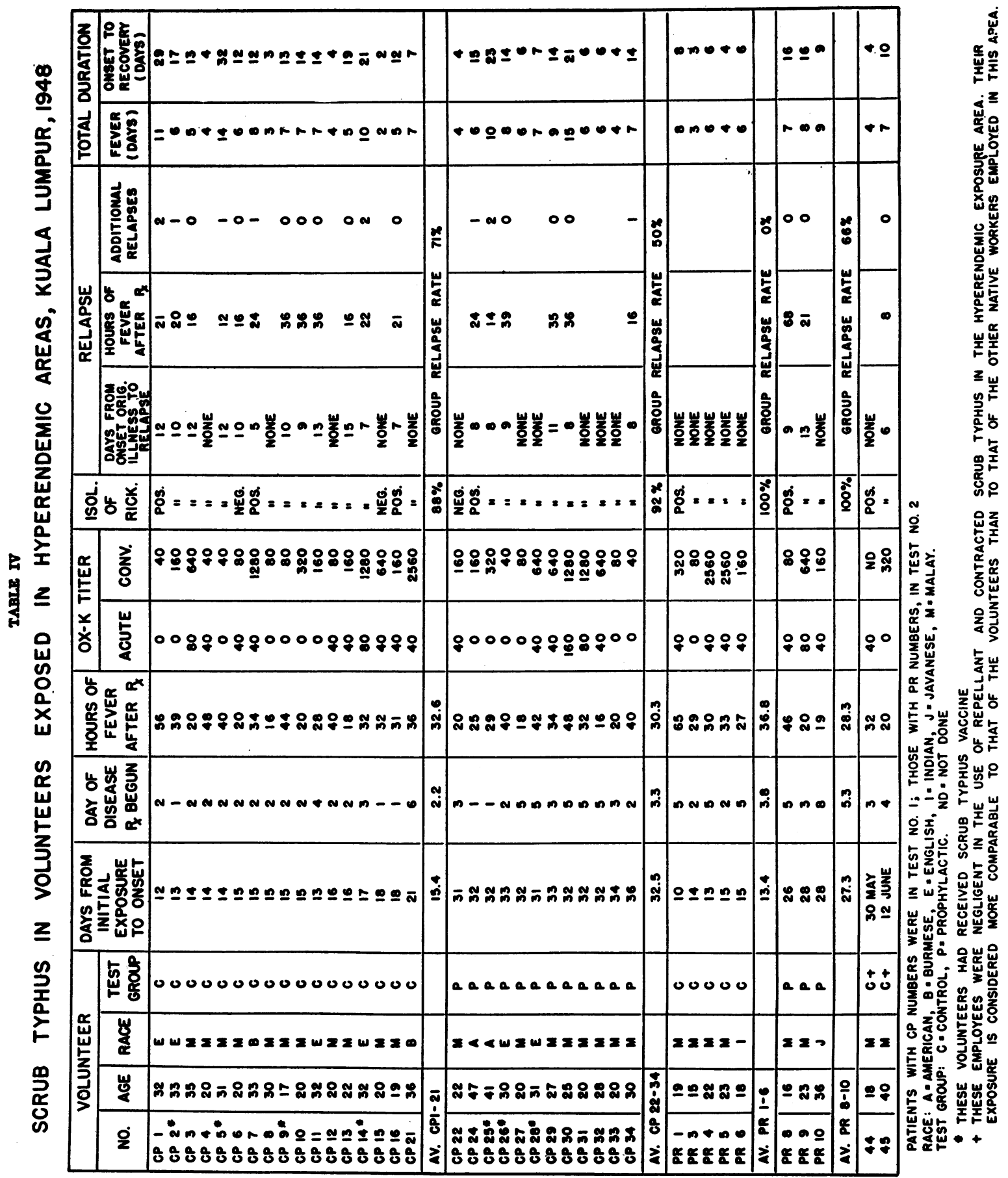


The record of volunteer Patient CP14, which is presented graphically in Figure 4, shows the usual course of the initial disease and the first relapse in the volunteers and the effect of therapy on these febrile episodes. This record also illustrates the findings in most of the individuals who had second and third relapses. It will be seen that this volunteer had a series of relatively mild febrile attacks and that he was ambulatory during most of the time covered by the chart, carrying on desk work but avoiding the more strenuous efforts of field work. The records of Patients CP4 and CP25 resemble that shown in Figure 4 in that these individuals also spent most of their time on duty between febrile episodes.

In contrast to the general rule that the volunteers who suffered from relapses were asymptomatic between their brief recurrent febrile episodes, were the findings in Patient CP30, whose record is summarized in Figure 5. This individual remained well until the 32nd day after the initial exposure which was ten days after his last prophylactic dose of chloromycetin. He was lost from observation from the 30th day after the first field exposure until the fifth day of his illness. At this time he was given 4.0 gms. of drug over a period of eight hours and became afebrile within 40 hours. As will be seen in Figure 5 the resultant afebrile period was of relatively short duration since low grade intermittent fever occurred during the ensuing week. The temperature reached $101^{\circ}$ F. on the 16th day after onset. At this time 3.0 gms. of drug were given in a single dose and the patient became permanently afebrile 40 hours later. It would appear that this was an instance in which the infection was controlled for only a brief period by the therapeutic regime employed. It is probable that the course of treatment used for Patient 1, who received 11.6 gms. of chloromycetin over 120 hours (Figure 2), would have been more appropriate in this instance. It may be mentioned that Patient CP30, along with CP21, spent 24 hours a day for nine days in the infected areas. These two, like the rest of the volunteers, received seven hours of supervised exposure daily but in addition they spent the remainder of the nine days of exposure in the areas serving as guards.

\section{Incidence of eschars in patients with scrub typhus}

The incidence of eschars in patients with scrub typhus has varied widely under different circumstances and in different geographic areas. Thus, during World War II the incidence of eschars observed in Allied troops from different combat areas ranged between 40 and 100 per cent (16-18). It

TABLE $v$

INCIDENCE OF ESCHARS IN PATIENTS WITH

SCRUB TYPHUS, KUALA LUMPUR, 1948

\begin{tabular}{|c|c|c|c|c|}
\hline GROUP & RACE & $\begin{array}{l}\text { NO. OF } \\
\text { CASES }\end{array}$ & $\begin{array}{l}\text { NO. WITH } \\
\text { ESCHARS }\end{array}$ & $\begin{array}{ll}\% & \text { WITH } \\
\text { ESCHARS }\end{array}$ \\
\hline $\begin{array}{c}\text { NATURALLY } \\
\text { OCCURRING CASES }\end{array}$ & $\begin{array}{l}\text { CAUCASIAN } \\
\text { ASIATIC } \\
\text { BOTH }\end{array}$ & $\begin{array}{r}6 \\
41 \\
47\end{array}$ & $\begin{array}{l}3 \\
3 \\
6\end{array}$ & $\begin{array}{r}50 \\
7 \\
13\end{array}$ \\
\hline $\begin{array}{l}\text { PROPHYLACTIC } \\
\text { FIELD TRIAL } \\
\text { NO DRUG }\end{array}$ & $\begin{array}{l}\text { CAUGASIAN } \\
\text { ASIATIC } \\
\text { BOTH }\end{array}$ & $\begin{array}{r}4 \\
18 \\
22\end{array}$ & $\begin{array}{l}4 \\
2 \\
6\end{array}$ & $\begin{array}{c}100 \\
11 \\
27\end{array}$ \\
\hline $\begin{array}{c}\text { PROPHYLACTIC } \\
\text { FIELD TRIAL } \\
\text { DRUG }\end{array}$ & $\begin{array}{l}\text { CAUCASIAN } \\
\text { ASIATIC } \\
\text { BOTH }\end{array}$ & $\begin{array}{l}4 \\
11 \\
15\end{array}$ & $\begin{array}{l}0 \\
0 \\
0\end{array}$ & $\begin{array}{l}0 \\
0 \\
0\end{array}$ \\
\hline TOTAL & $\begin{array}{l}\text { CAUCASIAN } \\
\text { ASIATIC } \\
\text { BOTH }\end{array}$ & $\begin{array}{l}14 \\
70 \\
84\end{array}$ & $\begin{array}{r}7 \\
5 \\
12\end{array}$ & $\begin{array}{r}50 \\
7 \\
14\end{array}$ \\
\hline
\end{tabular}


may be noted that the absence of this sign delayed the recognition of $R$. tsutsugamushi infections in northern Australia and Malaya $(10,11)$.

The present observations summarized in Table $\mathrm{V}$ reemphasize the marked variation in incidence of eschar formation in different groups of patients. Among the 47 patients with naturally acquired scrub typhus seen in the present study, six were Caucasians and the remainder Asiatics. Onehalf of the Caucasians developed eschars whereas only 7 per cent of the Asiatics showed this lesion. The frequency with which eschars appeared among the 37 volunteers who acquired scrub typhus following exposure in infected areas likewise appeared to be related to race but, in addition, was dependent upon whether chemoprophylaxis had been received. Thus, none of the four Caucasians and 11 Asiatics who had received chloromycetin prophylactically during the field trial developed eschars with their attack of scrub typhus, whereas all four Caucasians and two of 18 Asiatics who did not receive chloromycetin during their exposure developed an eschar.

These findings agree with earlier observations in Malaya $(10,11)$ that eschars are more frequently observed in Europeans than in Asiatics. They also indicate that the prophylactic administration of the specific drug during and following exposure influenced the formation of eschars. While no factual data are available to explain the role of prophylaxis in the eschar formation, it has been postulated elsewhere (15) that during the suppression of growth of rickettsiae by the drug, sufficient local immunity developed in the cutis at the site of the infected bite to prevent subsequent development of the eschar.

\section{Unusual cutaneous lesions in volunteers develop- ing scrub typhus}

An unusual skin eruption was observed on two of the volunteers (CP2 and CP14) in the first field trial. On the ninth day of exposure these individuals noted a number of small erythematous spots which itched slightly. These occurred in the axillae, groins, popliteal spaces, and around the waist, all areas where mite attachments are most apt to occur. These minor lesions persisted for several days and did not change during the prefebrile period when the primary eschar was developing in these two volunteers. Shortly after the onset of fever, when the primary eschar was already well developed, vesicles having a diameter of 2 to $4 \mathrm{~mm}$. and a height of 1 to $2 \mathrm{~mm}$. suddenly blossomed on the erythematous lesions. These looked like early varicella pocks but fluid could not be obtained when aspiration was attempted. Each volunteer had 50 to 100 vesicles which were limited almost entirely to the trunk, occurring primarily in the axillae and groins, and around the waist. The pock-like lesions receded a day or so after chloromycetin therapy was instituted but again flared up during the first relapse of both volunteers only to subside again when the fever disappeared. One of the volunteers, who was a physician, was convinced that at least six of the vesicles developed on marked sites where mites had been observed attached.

Neither histological studies nor attempts to recover rickettsiae from the lesions were undertaken. It is not possible to say whether these lesions represented unusual allergic reactions to mite bites which became infected during the rickettsemic phase of the disease; or whether they represented aborted primary eschars, occurring at the site of bites of infected mites acquired late in the exposure period, which were controlled by chemotherapy; or whether they were unrelated to scrub typhus.

\section{Chloromycetin in blood, spinal fluid, and milk}

The blood level of chloromycetin was determined on a number of occasions in each of the treated patients listed in Table III. Similar determinations were also made on selected patients with scrub typhus from the group of volunteers. There appears to be little point in discussing the blood levels in detail. In general, the data presented in Figures 2 and 3 illustrate the types of curves obtained in the prolonged and short courses of therapy.

The levels of chloromycetin in blood and spinal fluid specimens taken simultaneously were determined in three instances. In addition, on two occasions specimens of blood and milk, obtained at the same time from one of the lactating patients, were assayed. The results summarized in Table VI indicate that the level of chloromycetin in the spinal fluid is about half that found in the blood and that similarly the levels in the milk are of this same order of magnitude. 
TABLE VI

COMPARATIVE CHLOROMYCETIN LEVELS IN BLOOD, SPINAL FLUID AND MILK

\begin{tabular}{|c|c|c|c|c|}
\hline $\begin{array}{c}\text { PATIENT } \\
\text { NO. }\end{array}$ & DISEASE & $\begin{array}{c}\text { BLOOD } \\
\text { LEVEL } \\
\text { MG/CG. }\end{array}$ & $\begin{array}{c}\text { C.S.F. } \\
\text { LEVEL } \\
\text { MG./CG. }\end{array}$ & $\begin{array}{c}\text { MILK } \\
\text { LEVEL } \\
\mu G . / C G .\end{array}$ \\
\hline 18 & TYPHOID & 46 & 20 & \\
19 & TYPHOID & 21 & 9 & \\
37 & MALARIA & 37 & 10 & \\
24 & SCRUB & 49 & & 25 \\
$(8$ MOY) & & & & \\
$(94$ MOY $)$ & & 26 & & 16 \\
\hline
\end{tabular}

\section{Rickettsemia during afebrile periods}

The present work brought out a fact not previously recognized, namely, that $R$. tsutsugamushi may occur in the blood at times when a patient is afebrile and essentially asymptomatic. Patient $\mathrm{CP} 14$, one of the volunteers in the prophylactic trial, developed a lesion in the pretibial region of his left leg on the 15th day after initial exposure in the field. This vesicular lesion with a surrounding areola increased in size during the next few days while the patient remained ambulatory. Enlargement of the left inguinal nodes developed, and on the fifth day after its appearance the pretibial lesion was a typical eschar with a black center. It will be seen from Figure 4 that the patient had an elevation of temperature for the first time on the afternoon of the third day after the eschar was noted. A sample of blood obtained on the morning of this day contained $R$. tsutsugamushi. The rickettsial agent was again isolated from blood taken immediately before chloromycetin therapy was begun on the third febrile day of the illness. This is the first instance on record in which rickettsiae have been demonstrated in the blood prior to the febrile phase of scrub typhus.

From the very beginning of the present work we were interested in determining how rapidly rickettsiae disappeared from the blood of treated patients. Therefore, in treated Patient 1 blood samples were obtained at frequent intervals during the first two and one-half days after therapy

TABLE VII

\section{PERSISTENCE OF RICKETTSEMIA AFTER TREATMENT WITH CHLOROMYCETIN}

\begin{tabular}{|c|c|c|c|c|}
\hline \multirow{2}{*}{$\begin{array}{l}\text { SCRUB TYPHUS } \\
\text { CASE NO. }\end{array}$} & \multicolumn{2}{|c|}{ SPECIMEN TAKEN } & \multirow{2}{*}{$\begin{array}{c}\text { CHLOROMYCETIN } \\
\text { BLOOD LEVEL } \\
\text { MG. / CC. }\end{array}$} & \multirow{2}{*}{$\begin{array}{l}\text { RICKETTSIAE } \\
\text { IN BLOOD }\end{array}$} \\
\hline & $\begin{array}{c}\text { HOURS AFTER } \\
R_{x} \text { BEGUN }\end{array}$ & $\begin{array}{l}\text { PT'S. TEMP. } \\
\text { AT TIME }\end{array}$ & & \\
\hline 1 & $\begin{array}{l}\text { PRER } \\
4 \\
8 \\
12 \\
23 \\
30 \\
54\end{array}$ & $\begin{array}{r}102.8 \\
103.0 \\
100.8 \\
101.4 \\
98.4 \\
98.0 \\
97.8\end{array}$ & $\begin{array}{r}0 \\
27 \\
28 \\
16 \\
21 \\
13 \\
8\end{array}$ & $\begin{array}{l}\text { POS. } \\
\text { POS. } \\
\text { POS. } \\
\text { POS. } \\
\text { POS. } \\
\text { POS. } \\
\text { NEG. }\end{array}$ \\
\hline 4 & $\begin{array}{l}\text { PRER } \\
6\end{array}$ & $\begin{array}{l}102.0 \\
101.4\end{array}$ & $\begin{array}{r}0 \\
36\end{array}$ & $\begin{array}{l}\text { POS. } \\
\text { POS. }\end{array}$ \\
\hline 29 & $\begin{array}{l}\text { PRER } \\
17 \\
42\end{array}$ & $\begin{array}{r}102.2 \\
99.0 \\
98.0\end{array}$ & $\begin{array}{r}0 \\
45 \\
7\end{array}$ & $\begin{array}{l}\text { POS. } \\
\text { POS. } \\
\text { NEG. }\end{array}$ \\
\hline 43 & $\begin{array}{l}\text { PRER } \\
28\end{array}$ & $\begin{array}{r}101.8 \\
98.6\end{array}$ & $\begin{array}{r}0 \\
19\end{array}$ & $\begin{array}{l}\text { POS. } \\
\text { POS. }\end{array}$ \\
\hline 49 & $\begin{array}{c}\text { PRER } \\
1 / 2 \\
2 \\
6 \\
10 \\
24 \\
30 \\
48\end{array}$ & $\begin{array}{r}100.2 \\
101.6 \\
100.4 \\
102.6 \\
101.4 \\
98.6 \\
97.4 \\
97.4\end{array}$ & $\begin{array}{r}0 \\
15 \\
28 \\
100 \\
88 \\
26 \\
8 \\
0\end{array}$ & $\begin{array}{l}\text { POS. } \\
\text { POS. } \\
\text { POS. } \\
\text { POS, } \\
\text { POS. } \\
\text { POS. } \\
\text { POS. } \\
\text { NEG. }\end{array}$ \\
\hline
\end{tabular}

- THE MLDSO TITER Of THIS SPECIMEN In MICE WAS 10-1.5 
was begun and were used for isolation studies and for determination of chloromycetin blood levels. The data on this individual and on four other patients with scrub typhus who were investigated along these lines are given in Table VII. Several points are evident from the tabular material. In the first place, rickettsemia was demonstrated in three patients 28 to 30 hours after therapy was begun at which time the patients were afebrile. However, the rickettsiae had disappeared from the blood of these three patients 42 to 54 hours after therapy was instituted.

It has been shown that chloromycetin, even in concentrations of $1250 \mu \mathrm{g}$. per cc., has no in vitro rickettsiocidal activity against the agent of tsutsugamushi disease (19). Therefore, the presence
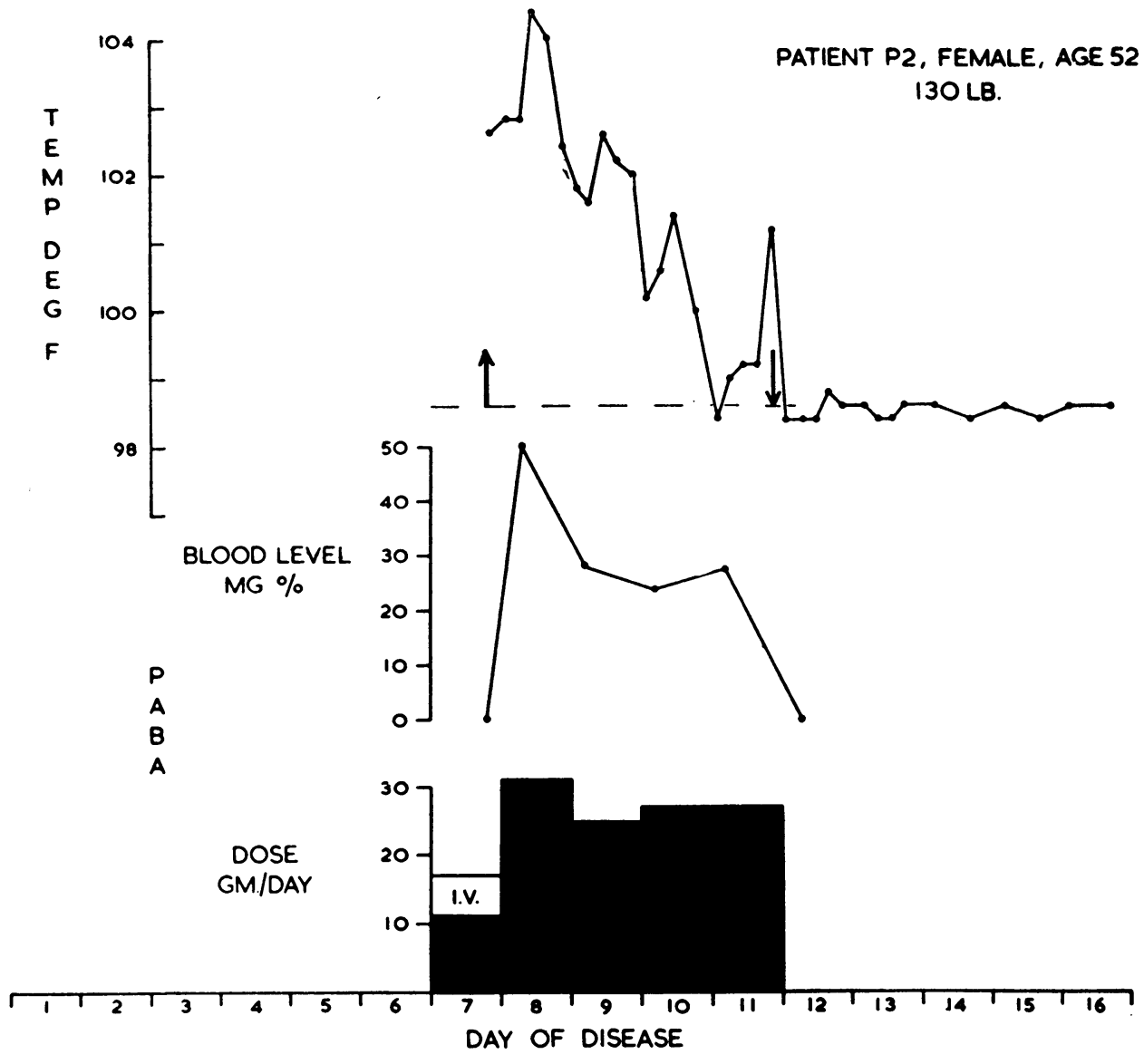

\begin{tabular}{|c|c|c|c|c|c|c|c|c|c|c|}
\hline RASH & + & \pm & 0 & & & & & & & \\
\hline ESCHAR & $+t$ & ++ & ++ & ++ & + & + & + & + & + & \pm \\
\hline WBC (THOUSANDS) & 8.6 & & & 9.7 & & & & 4.0 & & \\
\hline HBG (GM) & 12.2 & & & 12.0 & & & & 10.7 & & \\
\hline wF $O x-k$ & 40 & & & & & & & 1280 & & \\
\hline RICKETTSEMIA & + & & + & & & & & & & \\
\hline
\end{tabular}

Fig. 6. Clinical Response of Patient P2 to PABA Therapy Begun on the Seventh DAy of Disease

A total of 127.5 gms. of sodium p-aminobenzoate was given over a period 100 hours. 
of concentrations of 50 to $100 \mu \mathrm{g}$. per cc. of drug such as occurred in the patient's blood samples would not be expected to inactivate the organism. Furthermore, the relatively small amounts of drug present in the material inoculated into mice could not be expected to influence the infection in these animals.

\section{Para-aminobenzoic acid in the treatment of scrub typhus}

Para-aminobenzoic acid has been used with definitely beneficial results in the treatment of a number of rickettsial diseases $(20,21)$ including scrub typhus (22). Clinical results with this drug are less striking than are those obtained with the new antibiotic; nevertheless, when used relatively early in the disease, the duration of the febrile period and the mortality are reduced. Several patients with scrub typhus were treated with p-aminobenzoic acid while under our observation during the present work. The record of one of these, Patient P2, is illustrated in Figure 6. The results obtained in this individual correspond in general with those observed in the other two. The patient was admitted on the evening of the seventh day and at 8:00 p.m. received 6.0 gms. of sodium p-aminobenzoate intravenously. Between then and midnight she was given an additional 11.0 gms. of the drug by mouth. During the succeeding four days she received 25-30 gms. of sodium p-aminobenzoate daily. An adequate blood level was reached and maintained. The fever disappeared by lysis over four days and after the 12 th day the patient remained afebrile. In general, the results in our hands agreed with those obtained by Tierney (22) in the treatment of 18 patients with scrub typhus in Assam.

It is our opinion that p-aminobenzoic acid has a place in the treatment of this disease when the newer therapeutic agents are not available.

\section{Lack of toxic manifestations attributable to chlo- romycetin in treated patients}

No significant manifestations of toxicity were attributable to the use of chloromycetin in the treatment of 84 patients mentioned in this report; this includes not only 69 patients with scrub typhus but the additional group of 15 with other diseases. The occurrence of mild cerebral stimulation in persons receiving single $4.0 \mathrm{gm}$. doses of drug has been mentioned elsewhere as has the fact that the administration of 12.0 to 20.0 gms. of drug over a period of three weeks to 34 volunteers in the chemoprophylactic studies was without untoward effect (15). Most of the treated patients who had acquired their scrub typhus under strictly natural conditions received considerably smaller amounts of drug than did those volunteers in the chemoprophylactic tests who suffered from relapses. Even in the latter group no evidence of toxicity was demonstrated. It may be mentioned that certain of these volunteers, during the course of their prophylaxis and throughout their treatment, received 38.0 to 46.3 gms. of drug over a period of about eight weeks (see Table VIII). The administration of such large amounts of drug over an appreciable period of time indicates that patients are not readily sensitized to this substance. Even those individuals who received the compound intermittently remained free of evidence of sensitivity.

Red blood cell counts (or hemoglobin levels) and leukocyte counts were done, in so far as possible, both before treatment and during convalescence on all patients suffering from scrub typhus who received chloromycetin therapeutically. In five instances, when severely ill patients were treated in estate hospitals, it was not practicable to obtain pretreatment values. In the evaluation of data obtained in this fashion, it may be pointed out that a significant drop in red blood cell count, i.e., 0.9 million cells or 2.5 gms. of hemoglobin, occurs during the first two weeks of the untreated disease (23).

Of the 64 patients who received chloromycetin therapy for scrub typhus and who were adequately studied, 27 showed a drop in red blood cell count. The maximum decrease observed for any one patient was 1.10 million, and the average decrease for the entire group of 64 was 0.11 million. These reductions in red blood cell count are of the same order as those occurring in untreated patients (23). In the present group, there was an average rise of leukocyte count from 6,700 to 7,400 ; this also occurred frequently in untreated cases during convalescence. It is interesting to note that chloromycetin was administered to one patient whose leukocyte count at the beginning of therapy was only 1,700 . His recovery was uneventful, and, at the time of discharge, the white 


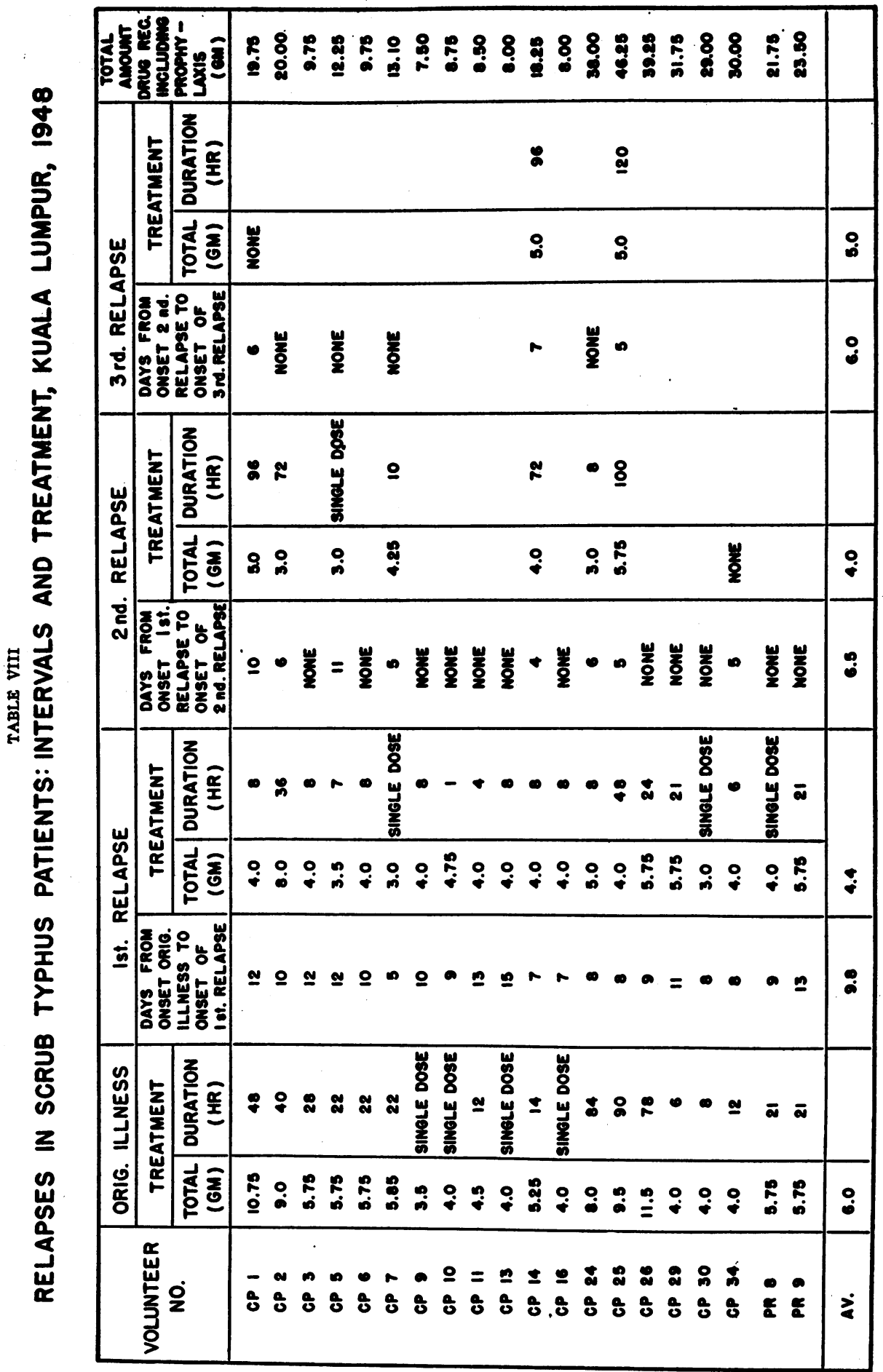


count had risen to 4,200. Routine urine analyses, performed during the acute illness and convalescence, demonstrated no abnormalities that were not present before therapy was initiated. In summary, no significant change of the blood or urine attributable to the administration of chloromycetin was noted.

\section{DISCUSSION}

The observations reported at this time clearly indicate that chloromycetin is a highly effective therapeutic agent in the treatment of scrub typhus in man. When properly used, it may be expected to produce obvious improvement in the patient's condition in a matter of a few hours and to render him afebrile in about 30 hours.

The short course of therapy which was used extensively in the present studies consisted of an initial oral administration of approximately 60 $\mathrm{mg} . / \mathrm{kg}$. of body weight which was followed by an additional 1.5 to $2.0 \mathrm{gms}$. of drug given as $0.25 \mathrm{gm}$. tablets at three-hour intervals. This regime appeared to be satisfactory in those patients who acquired their disease during exposure while pursuing their normal occupational duties. On the average these patients were first treated 6.2 days after onset of illness. These individuals all became afebrile in an average of 31.8 hours and remained afebrile thereafter.

The results in volunteers who were purposely exposed in hyperendemic areas of scrub typhus during the course of chemoprophylactic field trials differed from that observed in the patients who acquired the disease during normal occupational exposure in infected areas. Fifty-four per cent of the volunteers who developed scrub typhus subsequently had one or more relapses following the apparent cure which had resulted from the initial treatment. Although the volunteers who had relapses became permanently afebrile, on the average, on the 17th day after onset of original illness, nevertheless, a number of them did not return to full strength and vigor until two or three weeks later. Various factors which might have accounted for the relapse rate in the volunteers have been discussed at length in another paper. (15). Among these factors only two that need be mentioned here are (a) the infecting dose was undoubtedly heavy and was probably repeated over a period of days in the volunteers, and $(b)$ treat- ment was begun appreciably earlier in these persons than in those who acquired their infection naturally. The hypothesis which is presently preferred to account for these relapses is as follows: "The rickettsiostatic effect of chloromycetin was dissipated within a short time after therapy was stopped. At this early stage of infection the immune mechanism of the host had not yet had time to respond adequately to the rickettsial agent. Therefore, after a temporary interruption due to drug, the growth of the rickettsiae proceeded at an unabated rate. Finally, after an interval of five to 10 days, the rickettsial multiplication reached a level sufficient to elicit clinical manifestations again" (15).

The variation in incidence of eschars in patients of different races has been previously observed with scrub typhus $(10,11 b)$ and was the experience in the present studies on persons who acquired the disease during normal occupational duties. Furthermore, the high incidence of eschars in the Caucasians in the control chemoprophylactic group and the relatively low incidence in the Asiatics in this group was to be expected. However, the absence of eschars was an unexpected observation in those persons who developed scrub typhus after chemoprophylaxis was discontinued. It has been suggested that local cutaneous immunity developed in these persons during the subclinical infection which was brewing during the course of prophylaxis.

\section{SUMMARY AND CONCLUSIONS}

Sixty-nine patients with scrub typhus were treated with chloromycetin. Although some of these were desperately ill when therapy was instituted, there were no deaths in this group. The mortality rate among the 19 untreated patients observed during the present work was slightly greater than 5 per cent; this agrees well with the figure of 6.7 per cent in a series of 164 patients observed by Lewthwaite in Malaya (11a).

The most commonly used therapeutic regime in the present work employed about $6.0 \mathrm{gms}$. of chloromycetin orally over a period of 24 hours. This was adequate to render patients, who acquired their disease naturally, afebrile within an average of 32 hours irrespective of the time during the course of the disease when the drug was started. These patients convalesced rapidly and had no 
relapses. In contrast 54 per cent of the 37 volunteers who acquired scrub typhus developed relapses; these persons had been exposed for a number of days in hyperendemic areas during chemoprophylactic field trials. It is apparent that the course of therapy given early in the disease to volunteers was not adequate to control permanently the infection in them. However, the recrudescent disease was controlled without difficulty when chloromycetin was again administered. Additional information is needed before final conclusions can be drawn about the optimal therapeutic regime. In the meantime, it is recommended that all patients with scrub typhus, irrespective of the time when treatment is started, be given an initial oral dose of $60 \mathrm{mg} . / \mathrm{kg}$. of body weight and that this to be followed by $0.25 \mathrm{gm}$. doses of drug at three-hour intervals for at least 24 hours. If a recrudescence of fever occurs, the course should be repeated.

Chloromycetin is of low toxicity for man. No significant untoward effects were observed in any of the 84 patients who received the drug in the current studies.

Chloromycetin appears in the spinal fluid and milk of human beings reaching levels about half that in the blood.

Rickettsemia may occur for short periods before fever begins in tsutsugamushi disease and for a number of hours after treated patients become afebrile.

\section{ACKNOWLEDGMENTS}

The authors wish to thank the following members of the Royal Army Medical Corps, Lt. Col. R. H. Robinson, Officer in Charge, Major C. J. Williams, Medical Specialist, Lt. H. M. Giles, Graded Medical Specialist, and Major A. J. Rump, Registrar, of the Military Hospital, Kuala Lumpur, for their cooperation in the clinical evaluation of chloromycetin therapy of scrub typhus in military patients. Similarly, Dr. F. L. Choon, General Medical Officer, and Dr. C. N. Seong, Medical Officer, were of great help in the civilian General Hospital. Grateful acknowledgment is also made of the assistance provided by Miss E. B. Cheek, Dr. S. R. Savoor and other members of the staff of the Institute for Medical Research.

\section{BIBLIOGRAPHY}

1. Smadel, J. E., Woodward, T. E., Ley, H. L., Jr., Philip, C. B., and Traub, R., Chloromycetin in the treatment of scrub typhus. Science, 1948, 108, 160.

2. Ley, H. L., Jr., unpublished data.
3. Smith, R. M., Joslyn, D. A., Gruhzit, O. M., McLean, I. W., Penner, M. A., and Ehrlich, J., Chloromycetin : biological studies. J. Bact., 1948, 55, 425.

4. Irons, E. N., Clinical and laboratory variation of virulence in scrub typhus. Am. J. Trop. Med., 1946, 26, 165.

5. Plotz, H., The rickettsiae, in: Laboratory Methods of the United States Army. Edited by Simmons, J. S., and Gentzkow, C. J. Lea \& Febiger, Philadelphia, 1944, Ed. 5, pp. 575-576.

6. Plotz, H., Bennett, B. L., Wertman, K., Snyder, M. J., and Gauld, R. L., The serological pattern in typhus fever. I. Epidemic. Am. J. Hyg., 1948, $47,150$.

7. Turner, A., Micro method for determination of hemoglobin. Bull. U. S. Army M. Dept., 1946, 5, 605.

8. Bratton, A. C., and Marshall, E. K., Jr., New coupling component for sulfanilamide determination. J. Biol. Chem., 1939, 128, 537.

9. Fletcher, W., and Lesslar, J. E., Tropical typhus in the Federated Malay States. Bulletins from the Institute for Medical Research, Federated Malay States, No. 2 of 1925.

10. Fletcher, W., and Field, J. W., The tsutsugamushi disease in the Federated Malay States. Bulletins from the Institute for Medical Research, Federated Malay States, No. 1 of 1927.

11a. Lewthwaite, R., Clinical and epidemiological observations on tropical typhus in the Federated Malay States. Bulletins from the Institute for Medical Research, Federated Malay States, No. 1 of 1930.

b. Lewthwaite, R., and Savoor, S. R., Rickettsial diseases of Malaya. Identity of tsutsugamushi and rural typhus. Lancet, 1940, 1, 255 and 305.

12. Smadel, J. E., Jackson, E. B., Ley, H. L., Jr., and Lewthwaite, R., Comparison of synthetic and fermentation chloramphenicol (chloromycetin) in rickettsial and viral infections. Proc. Soc. Exper. Biol. \& Med., 1949, 70, 191.

13. Woodward, T. E., Smadel, J. E., Ley, H. L., Jr., Green, R., and Mankikar, D. S., Preliminary report on the beneficial effect of chloromycetin in the treatment of typhoid fever. Ann. Int. Med., 1948, 29, 131.

14. Ley, H. L., Jr.. Wondward. I. E., and Smadel, J. E., Chloramphenicol (chloromycetin) in the treatment of murine typhus. To be published.

15. Smadel, J. E., Traub, R., Ley, H. L., Jr., Philip, C. B., Woodward, T. E., and Lewthwaite, R., Chloramphenicol (chloromycetin) in the chemoprophylaxis of scrub typhus (tsutsugamushi disease). II. Results with volunteers exposed in hyperendemic areas of scrub typhus. Am. J. Hyg., 1949 , in press.

16. Blake, F. G., Maxcy, K. F., Sadusk, J. F., Jr., Kohls, G. M., and Bell, E. J., Studies on tsutsugamushi disease (scrub typhus, mite-borne typhus) in New Guinea and adjacent islands: Epidemiology, clinical observations and etiology in the Dobadura area. Am. J. Hyg., 1945, 41, 243. 
17. Philip, C. B., and Kohls, G. M., Studies on tsutsugamushi disease (scrub typhus, mite-borne typhus) in New Guinea and adjacent islands. Tsutsugamushi disease with high endemicity on a small South Sea island. Am. J. Hyg., 1945, 42, 195.

18. Philip, C. B., Woodward, T. E., and Sullivan, R. R., Tsutsugamushi disease (scrub or mite-borne typhus) in the Philippine Islands during American reoccupation in 1944-45. Am. J. Trop. Med., 1946, 26, 229.

19. Smadel, J. E., Jackson, E. B., and Cruise, A. B., Chloromycetin in experimental rickettsial infections. J. Immunol., 1949, 62, 49.
20. Snyder, J. C., The treatment of the rickettsial diseases of man, in The Rickettsial Diseases of Man. American Association for the Advancement of Science, Washington, 1948, pp. 171-174.

21. Woodward, T. E., and Raby, W. T., Further concepts in the treatment of Rocky Mountain spotted fever with para-aminobenzoic acid. South. M. J., 1948, 41, 997.

22. Tierney, N. A., Effect of para-aminobenzoic acid in tsutsugamushi disease. J. A. M. A., 1946, 131, 280.

23. Sayen, J. J., Pond, H. S., Forrester, J. S., and Wood, F. C., Scrub typhus in Assam and Burma; clinical study of 616 cases. Medicine, 1946, 25, 155. 